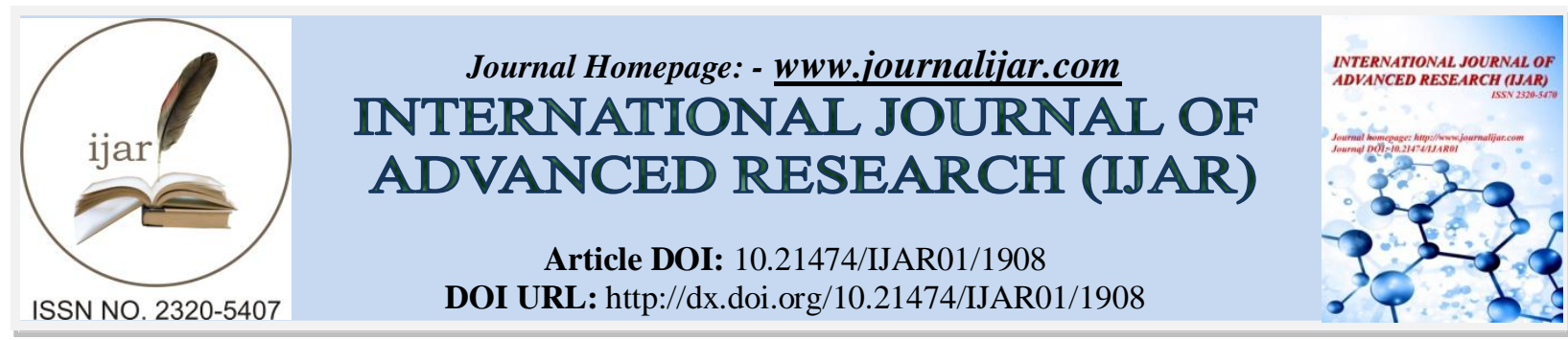

RESEARCH ARTICLE

\title{
MASS PRODUCTION AND FORMULATION OF AGRIBIOLOGICALS FROM PHOMA SP. (FGCC\#48) FOR THE MANAGEMENT OF AN IMPORTANT WEED-LANTANA CAMARA L.
}

*Sadaf Kalam and A.K. Pandey.

Mycology Research Laboratory, Department of Biological Sciences, R.D. University, Jabalpur, Madhya Pradesh, India.

\section{Manuscript Info}

Manuscript History

Received: 12 August 2016

Final Accepted: 16 September 2016

Published: October 2016

Key words:-

Agribiologicals, Lantana camara,

Phoma, agrowaste, mass production, formulation

\section{Abstract}

Biological control is the only cost-effective, environmentally benign and ecologically viable method available for the control of deadly weeds. Lantana camara is a global weed, which imposes deleterious economic effects on humans and livestock. Microbial products tend to offer a non-chemical alternative in controlling noxious, invasive and pernicious weeds like Lantana. Microbial secondary metabolites or agribiologicals are biotechnological products, which have provided new incentives for natural herbicidal products research. They are environmentally and toxicologically benign in comparison to traditional chemical herbicides. Phoma is a well-known phytopathogenic fungus known to produce an array of bioactive extracellular toxic compounds. Present work deals with screening various agrowastes for phytotoxin production at economically feasible rates followed by formulating them to facilitate their absorption and translocation within host foliar tissues. Herbicidal potential of test strain, was evaluated by shoot cut, seedling and detached leaf bioassays. Standardization and optimization of parameters for production of agribiologicals was achieved from Phoma sp. FGCC\#48. Arhar bran extract proved to be the best agrowaste, producing maximum phytotoxin, with tween 80 as a formulant @ $0.5 \%$ and this combination could be developed as a potential herbicide against the pernicious weed Lantana.

Copy Right, IJAR, 2016,. All rights reserved.

\section{Introduction:-}

Lantana camara belonging to family Verbenaceae, is a tropical weed, also known as prickly lantana or wild sage (Saraf et al., 2011) and has been ranked amongst top 100 most brunting invasive species on earth (Sharma et al., 2005). It is an erect perennial evergreen shrub with flowers changing to different colours. It is a weed of cultivated land, wasteland, roadsides and is a serious invader of natural ecosystems. It exhibits allelopathy i.e. toxicity of weeds to nearby vegetation which is mainly due to the release of toxins by seeds, leaves, twigs, roots, inflorescence and their residues (Holm et al., 1977).

Phytotoxicity of secondary metabolites of plant pathogens is well known. Phytotoxins avoid the environmental problems as encountered by use of chemicals. Extensive survey of literatures on phytotoxic metabolites clearly indicates that extensive work has been done on the role of toxins involved in diseases of economically important 
crops. There is very little work done on weed pathogens. However, consequences arisen by the indiscriminate use of synthetic herbicides have forced the scientists to search for new alternatives. Therefore, the phytotoxic potential of secondary metabolites of microorganisms associated with weeds has attracted the attention of a large number of scientists world over (Hoagland, 1999; Vikrant et al., 2006). The secondary metabolites appear to be a lucrative source of novel structures having unique mode of action which could be exploited as commercial herbicides directly or as their derivatives (Abbas et al., 1992; Quereshi et al., 2007). Several microbial products viz., Bialaphos, Gulfosinate, Tentoxin, Cornexistin, AAL-toxins, Fumonisin, Moniliformin etc have been successfully exploited for the management of many weeds (Hoagland, 2001; Barbosa et al., 2002). Agribiologicals is a term used for microbials, plant extracts, beneficial insects and other organic materials used by farmers to increase crop production (www.monsanto.com).

Mass production of secondary metabolites are known to be influenced by physicochemical factors viz., nutrients, temperature, $\mathrm{pH}$, static or rotary conditions (Saxena et al., 2001). To improve the efficacy or modify virulence, viability, host specificity or environmental requirement, formulations are required. Compatible formulation of the phytotoxins with suitable surfactants and adjuvants has expanded the spectrum of weeds controlled by a single application (Greaves et al., 2000). Absorption of herbicides and its translocation to the target site is of utmost importance, which comprise of a delivery system. The importance of efficient delivery to the target site as a fundamental requirement for herbicide activity and selectivity is generally recognized.

Various species and strains of the fungus synthesize a variety of phytotoxic secondary metabolites and few of them have also been evaluated for their herbicidal potential against many weeds (Evidente et al., 1998; Quereshi et al., 2006). Phoma is a well-known phytopathogen which incites various diseases in plants. Overall, fungi of the genus Phoma spp. are among the most prolific producers of secondary metabolites (Apoga et al., 2002). Survey conducted in various places of Central India yielded a highly pathogenic strain of Phoma sp from living leaves of Lantana. This fungal pathogen showed promising herbicidal potential against the weed Lantana camara. However being living product, bioactivity of the agent was found to be affected by environmental conditions. To overcome this problem, herbicidal property of the strain was evaluated and discussed in this paper. So the aim of this paper is to discover and mass produce phytotoxins or secondary metabolites which avoid these environmental problems encountered by chemicals and capable of preventing the spread of weed. Formulation of an agrobiological ideally results in a product that has low cost, long shelf-life, ease of application and efficacy. An array of phytotoxins have been known to be produced by Phoma spp. but their characterization and mass production using agrowastes is underway. Thus mass produced and formulated phytotoxic metabolites from Phoma sp. were evaluated for their herbicidal activities against the weed, Lantana in the present paper.

\section{Materials and methods:- \\ Recovery of strain:-}

Strain of Phoma sp. was isolated from phylloplane of the weed Lantana camara and was deposited in Fungal Germplasm Collection Center (FGCC) Mycological Research Laboratory, Department of Biological Sciences R.D.V.V. Jabalpur (M.P.). The fungus was maintained on Potato Dextrose Agar medium at $4 \pm 1^{0} \mathrm{C}$ for further studies.

\section{Screening of agrowastes for preparation of CFCF:-}

Five different agro based waste products were collected from the local market fields which included: malt, sugarcane bagasse, arhar bran, paper pulp and chana bran. Liquid extracts of these agro wastes were prepared for screening out the best agrowaste for mass production of phytotoxins.

\section{Preparation of liquid media extract:-}

1. Malt Extract Broth: $20 \mathrm{~g}$ of malt extract taken in $500 \mathrm{ml}$ distilled water was boiled for $60 \mathrm{~min}$, filtered through cheese cloth, then volume was raised up to 1 liter, and autoclaved $121^{\circ} \mathrm{C}, 15 \mathrm{lbs}$ for $15 \mathrm{~min}$.

2. Sugarcane Bagasse: $10 \mathrm{~g}$ of sugarcane bagasse taken in $300 \mathrm{ml}$ distilled water was boiled for $60 \mathrm{~min}$, filtered through cheese cloth, then volume was raised up to 1 liter, and autoclaved at $121^{\circ} \mathrm{C}, 15 \mathrm{lbs}$ for $15 \mathrm{~min}$.

3. Arhar Bran: $10 \mathrm{~g}$ of arhar bran taken in $300 \mathrm{ml}$ distilled water was boiled for $60 \mathrm{~min}$, filtered through cheese cloth, then volume was raised up to 1 liter, and autoclaved at $121^{\circ} \mathrm{C}, 15 \mathrm{lbs}$ for $15 \mathrm{~min}$.

4. Paper Pulp: $10 \mathrm{~g}$ of paper pulp taken in $300 \mathrm{ml}$ distilled water was boiled for $60 \mathrm{~min}$, filtered through cheese cloth, then volume was raised up to 1 liter, and autoclaved at $121^{\circ} \mathrm{C}, 15 \mathrm{lbs}$ for $15 \mathrm{~min}$. 
5. Chana Bran: $10 \mathrm{~g}$ of Chana bran taken in $300 \mathrm{ml}$ distilled water was boiled for $60 \mathrm{~min}$, filtered through cheese cloth, then volume was raised up to 1 liter, and autoclaved at $121^{\circ} \mathrm{C}, 15 \mathrm{lbs}$ for $15 \mathrm{~min}$.

\section{Fermentation:-}

$250 \mathrm{ml}$ Erlenmeyer flasks containing $50 \mathrm{ml}$ of different extracts were autoclaved at $121^{\circ} \mathrm{C}$ and $15 \mathrm{lbs}$ pressure for 15 minutes and then were seeded with 7 days old actively growing culture with the help of $5 \mathrm{~mm}$ sterilized cork borer, and incubated at different temperatures and $\mathrm{pH}$ levels.

\section{Extraction of CFCF:-}

CFCF was aseptically obtained by filtering the metabolized growth medium through Whatman filter paper No. 1. The supernatant was filtered through the sartorius filter paper $0.45 \mu \mathrm{m}$, Minisart (Sartorius Gottingen, Germany) millipore filter under in vасио conditions (Walker and Templeton, 1978).

\section{Effect of Temperature:-}

Sterilized extract of arhar bran was seeded with 7 days old actively growing culture of Phoma sp. and incubated at different temperatures viz., $5,15,25,28,35$ and $45^{\circ} \mathrm{C}$ for 21 days. Mass production of phytotoxins at different temperatures was thus studied and phytotoxicity of the CFCF was determined by shoot cut and detached leaf bioassay.

\section{Effect of pH:-}

Similarly the strain of Phoma sp. was inoculated in the sterilized extract of Arhar bran maintained at different $\mathrm{pH}$ levels viz., 3, 4, 5, 6, 7, 8 with the help of $0.1 \mathrm{M} \mathrm{HCl}$ and $0.1 \mathrm{M} \mathrm{NaOH}$ solution and incubated for 21 days at 28 $\pm 2^{\circ} \mathrm{C}$. Mass production of phytotoxins at different $\mathrm{pH}$ was observed and phytotoxic damage rating was assessed by shoot cut and detached leaf bioassays.

\section{Formulation:-}

To test the compatibility of the phytotoxin synthesized by the pathogen ten formulating agents namely, Tween 80 , Tween 20, soyabean oil, mustard oil, coconut oil, groundnut oil, Triton X-100, sucrose, glycerol, sorbitol were used. Formulating agents were added at the rate of $0.5 \%$ to the toxin and its herbicidal potential was determined by detached leaf bioassay and seedling bioassay (Quereshi et al., 2010).

\section{Bioassay:-}

Experiments viz., shoot cut bioassay, seedling bioassay and detached leaf bioassay were performed according to the methods adopted by Vikrant et al., 2006 and Kalam et al., 2014.

In all the bioassays, sterilized non- metabolized growth medium was used as control and distilled water (DW) served as control over control. All the treatments were carried out in triplicates and all the bioassays were repeated atleast thrice.

\section{Result and Discussion:-}

Numerous advantages can be attributed to the use of liquid culture fermentation or submerged fermentation for the production of herbicides. As liquid or submerged fermentations are relatively low cost, automated processes can be scaled up to very large volumes. Thus, liquid or submerged fermentation has been the method of choice for the large-scale production of phytotoxins. Data presented in Table 1 reveals significant variation in mycelial biomass caused by cell free culture filtrates obtained by cultivating Phoma sp. (FGCC\#48) on different agrowaste extracts. Extensive mycelial growth was observed in three agrowastes taken out of five experimented. However, maximum growth was observed in arhar bran extract followed by malt extract and chana bran extract. sugarcane bagasse extract and paper pulp extract yielded negligible mycelial biomass. There was an increase in initial acidic $\mathrm{pH}$ in extract viz., arhar bran extract towards alkaline side.

Shoot cut bioassay was also performed with different agrowaste fungal extracts and the results are represented in Table 1. Maximum phytotoxic damage to Lantana shoots occurred with arhar bran extracts. Maximum foliar damage was recorded with fermented media containing arhar bran extract followed by malt extract and chana bran extract. Negligible quantities of toxins were produced in sugarcane bagasse extract and paper pulp extract. Sugarcane bagasse has been effectively used for growing fungal mycelium (Sidana and Farooq, 2014). 
Table 1:- Changes in $\mathrm{pH}$ due to fungal growth and phytotoxicity damaging rate (Shoot Cut Bioassay).

\begin{tabular}{|l|l|l|l|l|l|}
\hline S.No. & Substrates/ Agrowastes & Initial $\mathbf{~ p H}$ & Final $\mathbf{~ p H}$ & $\begin{array}{l}\text { Biomass } \\
(\mathbf{g m} / \mathbf{1 5 0} \mathbf{~ m l})\end{array}$ & $\begin{array}{l}\text { Phytotoxicity Damaging } \\
\text { Rate (PDR) }\end{array}$ \\
\hline & & & & Mean \pm SD & Mean \pm SD (after 48 hours) \\
\hline 1 & Arhar Bran & 6.48 & 7.8 & $0.886 \pm 0.15$ & $4.5 \pm 0.33$ \\
\hline 2 & Malt Extract & 5.6 & 7.9 & $0.843 \pm 0.025$ & $3.8 \pm 0.43$ \\
\hline 3 & Chana Bran & 6.37 & 7.7 & $0.166 \pm 0.15$ & $3.2 \pm 0.12$ \\
\hline 4 & Sugarcane Bagasse & 7.1 & 7.3 & $0.166 \pm 0.77$ & $3.9 \pm 0.66$ \\
\hline 5 & Paper Pulp & 8.27 & 6.6 & $0.013 \pm 0.77$ & $0.99 \pm 0.33$ \\
\hline
\end{tabular}

Detached leaf bioassay was also performed with fungal extracts and results are represented in Table 2. Results are in agreement with those obtained in shoot cut bioassay. Arhar bran fungal extract produced maximum phytotoxic damage to Lantana leaves after $48 \mathrm{hpt}$. While no damage was observed with sugarcane bagasse and paper pulp metabolized broths. For mass production of phytotoxins, a cheaper and economically feasible media is a prerequisite. Results of various agrowastes for mass production of phytotoxin from Phoma sp. (FGCC\#48) clearly indicate that best phytotoxin production was achieved in arhar bran extract. So arhar bran extract was employed as the basal medium. Similarly, Parra et al.,2005 have optimized the composition and concentration of a liquid fermentation medium for the production of phytotoxins from Phoma sp.

Table 2:- Determination of phytotoxicity damaging rate through Detached Leaf Bioassay.

\begin{tabular}{|l|l|l|l|l|}
\hline S.No. & Substrates/ Agrowastes & After 12 Hour & After 24 Hour & After 48 Hour \\
\hline & & Mean \pm SD & Mean \pm SD & Mean \pm SD \\
\hline 1 & Arhar Bran & $2.85 \pm 0.9$ & $3.88 \pm 0.09$ & $5.00 \pm 0.00$ \\
\hline 2 & Malt Extract & $1.77 \pm 0.11$ & $2.12 \pm 0.9$ & $4.22 \pm 1.66$ \\
\hline 3 & Chana Bran & $1.44 \pm 0.11$ & $1.98 \pm 0.39$ & $2.88 \pm 0.12$ \\
\hline 4 & Sugarcane Bagasse & $0.20 \pm 0.0$ & $0.29 \pm 0.06$ & $1.66 \pm 0.8$ \\
\hline 5 & Paper Pulp & $0.11 \pm 0.74$ & $0.88 \pm 0.38$ & $1.00 \pm 0.00$ \\
\hline
\end{tabular}

Since, mass production of fungal metabolites is precondition for field trials, alternatives to costly chemicals are always in demand by the agrochemical industries. Various agrochemical wastes have been employed by researchers for cost-effectiveness of the final herbicidal product (Akinyele and Adetuyi, 2005). Being locally and readily available these agricultural byproducts could be novel and productive sources for large scale production of ecofriendly agribiologicals. Arhar bran extract has been documented to be the best agrowaste supporting maximum phytoxin production (Quereshi et al., 2010; Kalam et al., 2014).

As depicted in Table 3 phytotoxin production was observed to be maximum in 21 days old fermented arhar bran extract, followed by 28 days, 14 days and 7 days respectively. There was a gradual increase in $\mathrm{pH}$ during fermentation process from 7 days to 28 days. Similarly biomass also showed similar trend with minimum value observed after 7 days of incubation and maximum observed after 28 days of incubation.

Table 3:- Determination of effect of different incubation periods on biomass production and phytotoxicity damage employing Shoot Cut Bioassay.

\begin{tabular}{|l|l|l|l|l|l|}
\hline S.No. & $\begin{array}{l}\text { Incubation } \\
\text { Period }\end{array}$ & Final $\mathbf{~ p H}$ & $\begin{array}{l}\text { Biomass } \\
(\mathbf{g m} / \mathbf{1 5 0} \mathbf{~ m l})\end{array}$ & $\begin{array}{l}\text { Phytotoxicity Damaging } \\
\text { Rate (PDR) (after 48 Hour) }\end{array}$ & Final pH \\
\hline & & & Mean \pm SD & Mean \pm SD & \\
\hline 1 & 7 days & 6.52 & $0.58 \pm 0.02$ & $0.073 \pm 0.02$ & 6.52 \\
\hline 2 & 14 days & 6.71 & $0.713 \pm 0.04$ & $2.696 \pm 0.2$ & 6.71 \\
\hline 3 & 21 days & 6.91 & $0.526 \pm 0.08$ & $4.73 \pm 0.7$ & 6.91 \\
\hline 4 & 28 days & 7.24 & $0.59 \pm 0.04$ & $4.36 \pm 0.7$ & 7.24 \\
\hline
\end{tabular}

A sharp difference in phytotoxicity with increasing incubation period may be credited to different phases of growth of the growing fungus. Metabolites are also required for the growth of fungus itself and are normally synthesized during initial phase whereas most of the toxicants are produced during stationary phase i.e. idiophase of the mould. The production of fungal secondary metabolites is reportedly dependant on the physico-chemical factors surrounding the mould. Hydrogen ion concentration of the cultivating media affects phytotoxin production. The effect of different $\mathrm{pH}$ on the biomass and phytotoxin production by the fungi employed in the present study are 
shown in Table 4. Biomass production was clearly retarded at higher $\mathrm{pH}$. $\mathrm{pH} 4$ supported maximum biomass production followed by $\mathrm{pH} 3.0$ and 5.0. While higher $\mathrm{pH}$ level viz., 6,7 and 8 did not support significant mycelial dry weight.

Table 4:- Determination of effect of different $\mathrm{pH}$ levels on biomass production and phytotoxicity damage employing Shoot Cut Bioassay.

\begin{tabular}{|l|l|l|l|l|}
\hline S.No. & Initial pH & Final pH & Biomass (gm/150ml) & $\begin{array}{l}\text { Phytotoxicity Damaging Rate } \\
\text { (PDR) (after 48 Hour) }\end{array}$ \\
\hline & & & Mean \pm SD & Mean \pm SD \\
\hline 1 & 3.0 & 6.43 & $0.69 \pm 0.04$ & $4.12 \pm 0.5$ \\
\hline 2 & 4.0 & 7.62 & $0.646 \pm 0.04$ & $4.6 \pm 0.2$ \\
\hline 3 & 5.0 & 6.9 & $1.083 \pm 0.28$ & $4.0 \pm 0.2$ \\
\hline 4 & 6.0 & 7.4 & $0.943 \pm 0.34$ & $3.5 \pm 0.1$ \\
\hline 5 & 7.0 & 7.2 & $0.856 \pm 0.18$ & $2.83 \pm 0.33$ \\
\hline 6 & 8.0 & 8.2 & $1.02 \pm 0.56$ & $0.93 \pm 0.06$ \\
\hline
\end{tabular}

With regards to phytotoxicity, Arhar bran fermented extract at $\mathrm{pH} 4$ showed maximum phytotoxic damage to Lantana shoots followed by $\mathrm{pH} 3$ and $\mathrm{pH}$ 5. Toxin production in Arhar bran extract of $\mathrm{pH}$ 6, 7 and 8 was negligible and therefore failed to cause significant phytotoxic damage to Lantana shoots. Results of detached leaf bioassay performed with Arhar bran fungal extracts obtained at different $\mathrm{pH}$ levels are depicted in Table 5. Earlier workers have recorded an optimum $\mathrm{pH} 4$ for phytotoxin production for other fungi (Pandey et al., 2001, 2004). Analogous results regarding $\mathrm{pH}$ optima of Arhar bran fermented fungal CFCF have been documented (Kalam et al., 2014).

Table 5:- Determination of effect of different $\mathrm{pH}$ levels on biomass production and phytotoxicity damage employing Detached Leaf Bioassay.

\begin{tabular}{|l|l|l|l|l|}
\hline S.No. & pH & Phytotoxicity Damaging Rate (PDR) & \\
\hline & & After 12 hour & After 24 Hour & After 48 Hour \\
\hline 1 & 3.0 & $3.3 \pm 0.40$ & $3.7 \pm 0.26$ & $4.3 \pm 0.2$ \\
\hline 2 & 4.0 & $3.72 \pm 0.13$ & $4.5 \pm 0.21$ & $4.9 \pm 0.11$ \\
\hline 3 & 5.0 & $2.54 \pm 0.4$ & $3.4 \pm 0.6$ & $4.08 \pm 0.4$ \\
\hline 4 & 6.0 & $2.2 \pm 0.2$ & $2.3 \pm 0.1$ & $3.3 \pm 0.1$ \\
\hline 5 & 7.0 & $1.30 \pm 0.00$ & $1.44 \pm 0.19$ & $1.66 \pm 0.00$ \\
\hline 6 & 8.0 & $0.29 \pm 0.06$ & $0.40 \pm 0.064$ & $0.77 \pm 0.00$ \\
\hline
\end{tabular}

Results were consistent with those obtained from shoot cut bioassay. Toxin produced at $\mathrm{pH} 4$ produced maximum foliar damage within $12 \mathrm{hpt}$, which enhanced till $48 \mathrm{hpt}$. Phytotoxic effect by the toxin was minimum after $12 \mathrm{hpt}$ after $12 \mathrm{hpt}$ and maximum after $48 \mathrm{hpt}$. Similar trend was also recorded by earlier workers (Pandey et al., 2001, 2004).Thus $\mathrm{pH} 4$ was optimum for phytotoxin production where highest quantities of toxic metabolite production was observed.

The incubation temperature is one of the significant parameter in determining the overall growth and development of any organism. Effect of different incubation temperatures on growth and phytotoxin production by Phoma (FGCC\#48) was studied by shoot cut bioassay on Lantana shoots and is shown in Table 6. Lower temperature neither favoured fungal growth nor phytotoxin production.

Table 6:- Determination of effect of different temperatures on biomass production and phytotoxicity damage employing Detached Leaf Bioassay.

\begin{tabular}{|l|l|l|l|}
\hline S.No. & Temperature $^{\circ} \mathbf{C}$ & Biomass $(\mathbf{g m} / \mathbf{1 5 0 m l})$ & Phytotoxicity Damaging Rate (PDR) \\
\hline & & Mean \pm SD & Mean \pm SD \\
\hline 1 & 5 & $0.106 \pm 0.08$ & $0.66 \pm 0.0$ \\
\hline 2 & 15 & $0.116 \pm 0.04$ & $4.11 \pm 0.88$ \\
\hline 3 & 25 & $1.43 \pm 0.7$ & $4.87 \pm 0.4$ \\
\hline 4 & 28 & $1.86 \pm 0.2$ & $4.9 \pm 0.1$ \\
\hline 5 & 35 & $1.59 \pm 0.08$ & $2.5 \pm 0.15$ \\
\hline 6 & 45 & $0.823 \pm 0.07$ & $1.6 \pm 0.1$ \\
\hline
\end{tabular}

Maximum mycelial biomass production was achieved at $28^{\circ} \mathrm{C}$ followed by $25^{\circ} \mathrm{C}$ and $35^{\circ} \mathrm{C}$. No significant growth and phytotoxin was reported at lower and higher incubation temperatures. Phytotoxin produced at $28^{\circ} \mathrm{C}$ produced 
remarkable phytotoxicity. Phytotoxic damage on Lantana leaves on treatment with toxin produced at various incubation temperatures is given in Table 7. Phytotoxin produced at $28^{\circ} \mathrm{C}$ exhibited maximum damage to the leaves, followed by $25^{\circ} \mathrm{C}, 35^{\circ} \mathrm{C}$ and $45^{\circ} \mathrm{C}$. Results are consistent with those obtained by shoot cut bioassay. Significant variation in phytotoxin production by other fungi at various temperatures have also been observed (Pandey et al.,2004; Singh et al., 2010).

Table 7:- Detached Leaf Bioassay with Arhar bran extract to study effect of different temperatures.

\begin{tabular}{|c|c|c|c|c|}
\hline S.No. & Temperature ${ }^{\circ} \mathbf{C}$ & \multicolumn{3}{|c|}{ Phytotoxicity Damaging Rate (PDR) } \\
\hline & & After 12 hour & After 24 Hour & After 48 Hour \\
\hline & & Mean \pm SD & Mean \pm SD & Mean \pm SD \\
\hline 1 & 5 & $0.0 \pm 0.05$ & $0.106 \pm 1.1$ & $0.22 \pm 0.4$ \\
\hline 2 & 15 & $0.1 \pm 0.04$ & $0.23 \pm 0.05$ & $0.24 \pm 0.04$ \\
\hline 3 & 25 & $1.4 \pm 0.6$ & $1.52 \pm 0.66$ & $3.04 \pm 0.7$ \\
\hline 4 & 28 & $3.0 \pm 0.07$ & $3.6 \pm 0.5$ & $4.6 \pm 0.4$ \\
\hline 5 & 35 & $2.0 \pm 0.2$ & $2.18 \pm 0.25$ & $2.3 \pm 0.05$ \\
\hline 6 & 45 & $1.3 \pm 0.14$ & $1.5 \pm 0.00$ & $1.73 \pm 0.6$ \\
\hline
\end{tabular}

Data recorded in Table 8 clearly indicates that maximum seedling mortality was observed with combination of phytotoxin and Tween 80 followed by other formulants, Tween 20 and soyabean oil after 48 hpt. Thus Tween 80 was found to be highly compatible with phytotoxin. Mustard oil, coconut oil, groundnut oil and Triton X-100 showed average compatibility. Phytotoxic damage observed was maximum after $48 \mathrm{hpt}$, average at $24 \mathrm{hpt}$ and minimum after $12 \mathrm{hpt}$.

Table 8:- Seedling Bioassay for determining best formulant.

\begin{tabular}{|l|l|l|l|l|}
\hline S.No. & Formulating Agent & Phytotoxic Damaging Rate & \\
\hline & & After 12 hpt & After 24 hpt & After 48 hpt \\
\hline 1 & Tween 80 & $2.3 \pm 0.7$ & $3.7 \pm 0.11$ & $4.75 \pm 0.2$ \\
\hline 2 & Tween 20 & $2.4 \pm 0.11$ & $3.0 \pm 0.35$ & $4.5 \pm 0.2$ \\
\hline 3 & Soybean Oil & $1.5 \pm 0.1$ & $2.3 \pm 0.11$ & $2.2 \pm 0.0$ \\
\hline 4 & Mustard Oil & $0.69 \pm 0.09$ & $1.2 \pm 0.6$ & $1.9 \pm 0.17$ \\
\hline 5 & Coconut Oil & $0.4 \pm 0.08$ & $1.006 \pm 0.22$ & $1.14 \pm 0.11$ \\
\hline 6 & Ground nut Oil & $0.16 \pm 0.04$ & $0.24 \pm 0.15$ & $0.4 \pm 0.07$ \\
\hline 7 & Triton X-100 & $0.3 \pm 0.15$ & $0.4 \pm 0.05$ & $0.56 \pm 0.21$ \\
\hline 8 & Sucrose & $0.03 \pm 0.15$ & $0.16 \pm 0.11$ & $0.5 \pm 0.00$ \\
\hline 9 & Glycerol & $0.01 \pm 0.0$ & $0.06 \pm 0.03$ & $0.3 \pm 0.06$ \\
\hline 10 & Sorbitol & $0.00 \pm 0.100$ & $0.04 \pm 0.01$ & $0.08 \pm 0.01$ \\
\hline
\end{tabular}

Arhar bran fungal extract containing agrochemical was also tested for its compatibility with different formulating agents employing detached leaf bioassay, results observed are given in Table 9. The formulating agent proving to be the most compatible imparting maximum damage to Lantana leaves was Tween 80 after $48 \mathrm{hpt}$ as assessed through seedling and detached leaf bioassay..

Table 9:- Detached leaf bioassay for determining best formulant

\begin{tabular}{|l|l|l|l|l|}
\hline S.No. & Formulating Agent & \multicolumn{4}{l|}{ Phytotoxic Damaging Rate } & After 48 hpt \\
\hline & & After 12 hpt & After 24 hpt & $4.998 \pm 0.192$ \\
\hline 1 & Tween 80 & $4.666 \pm 0.034$ & $4.889 \pm 0.193$ & $4.222 \pm 0.193$ \\
\hline 2 & Tween 20 & $4.111 \pm 0.192$ & $4.132 \pm 0.024$ & $3.999 \pm 0.123$ \\
\hline 3 & Soybean Oil & $3.499 \pm 0.322$ & $3.840 \pm 0.311$ & $2.999 \pm 0.24$ \\
\hline 4 & Mustard Oil & $2.332 \pm 0.192$ & $2.338 \pm 0.194$ & $2.224 \pm 0.24$ \\
\hline 5 & Coconut Oil & $2.111 \pm 0.110$ & $2.124 \pm 0.112$ & $1.224 \pm 0.12$ \\
\hline 6 & Ground nut Oil & $1.084 \pm 0.04$ & $1.118 \pm 0.006$ & $1.123 \pm 0.11$ \\
\hline 7 & Triton X-100 & $1.003 \pm 0.02$ & $1.008 \pm 0.03$ & $0.045 \pm 0.03$ \\
\hline 8 & Sucrose & $0.023 \pm 0.01$ & $0.040 \pm 0.04$ & $0.10 \pm 0.01$ \\
\hline 9 & Glycerol & $0.008 \pm 0.0$ & $0.08 \pm 0.11$ & $0.042 \pm 0.10$ \\
\hline 10 & Sorbitol & $0.010 \pm 0.2$ & $0.018 \pm 0.11$ & \\
\hline
\end{tabular}

Note: Values are means of three replicates with Standard Deviation. 


\section{Except for temperature optimization experiments, the experimental conditions were: \\ R.H-80\% Room Temp. $-28 \pm 1^{\circ} \mathrm{C}$ Sterilized non- metabolized growth medium- control Control over control - Distilled water (DW)}

Order of compatibility was- Tween $80>$ Tween 20>Soyabean>oil Mustard Oil $>$ Coconut oil $>$ Groundnut Oil $>$ Triton X-100>Sucrose $>$ Glycerol>Sorbitol.

Thus, variations in different formulations may be due to different degrees of compatibility of the phytotoxin residing in CFCF with various formulating agents. Zhang et al., 2003 have screened similar adjuvants for bioherbicide formulations with Phoma spp.

The results of shoot cut bioassay indicate that toxicity appeared initially and reached its zenith after 48 hpt. Leaves exhibited severe chlorosis and necrosis. The toxicity initiated at the tip of leaf blades and spreaded to the entire lamina. Blackening of stem was also observed with dropping and curling of upper leaves finally culminating in shoot death.

The results of seedling bioassay indicate that toxicity appeared by the emergence of necrotic and chlorotic spots on the leaves. Phytotoxicity was proportional to time of exposure. Loss of turgidity, drying finally culminated into seedling collapse. Similar results have been reported by (Abbas and Boyette, 1992; Quereshi et al., 2010). Detached leaf bioassay results depict toxicity which initiated with slight necrosis and at advanced stage after 48 hpt acute necrosis was observed with wilting of entire leaves leading to complete death of foliar tissue

Formulation is a process of mixing the secondary metabolite or the microbe with some inert carriers to alter their physico-chemical characteristics to enhance the shelf life and field performance of resulting formulated product. It involves the use of certain agents called as the formulants, which include: adjuvants, surfactants, wetting agents, spreaders and penetrants. Adjuvants act by effectively increasing the absorption of post emergence herbicides by enhancing the wettability of the target area by reducing surface tension. Adjuvants also enhance penetration (Singh and Mack, 1993). Optimization of composition and concentration of a liquid fermentation medium for Phoma spp. phytotoxin production has been done by Parra et al. (2005). Performance efficiency is largely dependent upon surfactants which reduce the amount of active herbicide required and improve pesticide safety. Tween series of surfactants are nonionic surfactants, which adsorb with the alkyl chain at the hydrophobic surface (Graca et al., 2007) and are generally easily degradable. Oils are effective surfactants as they reduce vapour loss of herbicide thereby enhancing herbicide performance (Gauvrit and Cabanne, 1993).

Fungal ecofriendly agribiologicals or fungal phytotoxins are plant protection molecules gaining momentum for agrichemical research nowadays. Our research group has actively been involved with isolation of phytopathogenic fungi, extraction of phytotoxins, determination of their herbicidal potential and mass production and formulation of herbicidal metabolites. We have earlier isolated phytotoxins from various Phoma spp. for management of some prominent weeds of Central India. Similarly phytotoxins from Phoma sp. FGCC\#18 have been tested for their compatibility with different formulants for biocontrol of deadly weed Parthenium. Phytotoxicity damage had been studied by seedling and detached leaf bioassays. Results indicate, Tween 80 at $0.5 \%$ to be the best formulant, while the combination of Tween 80 and coconut oil at $0.5 \%$ was found to exhibit maximum damage to Parthenium seedlings and detached leaves (Quereshi et al., 2010). Thus in our present research work, results were in accordance to results obtained earlier wherein, Tween 80 has been reported to be most compatible formulant (Kalam et al., 2014). Evaluation of agrochemicals blended with formulants against Hyptis suaveolens (Naseem et al., 2016) indicate similar results wherein, maximum phytotoxicity has been obtained from 21 days old fermented broth with Tween $80 @ 0.5 \%$ as formulating agent.

In all the experiments, sterilized non- metabolized growth medium (control) and Distilled water (DW) (control over control) showed neither biomass production nor phytotoxicity.

In order to scrutinize the compatibility of the Phoma sp. FGCC\#48 phytotoxins, various formulants were tested. Results obtained above, indicate that the secondary metabolites of Phoma sp. FGCC\#48 could be mass produced using arhar bran extract as an agrowaste, with tween 80 as a formulant @ 0.5\% and this combination could be developed as a potential herbicide for the management of a prominent weed of Central India, Lantana camara. 


\section{Acknowledgement:-}

The authors are thankful to the Head, Department of Biological Sciences, R.D. University Jabalpur, for laboratory facilities. Madhya Pradesh Biotechnology Council, MPCOST, and DoEN are also thankfully acknowledged for providing financial assistance.

\section{References:-}

1. Abbas, H.K., and Boyette, C.D. (1992). Phytotoxicity of fumonisin B1 on weed and crop species. Weed Technol. 6:548-552.

2. Abbas, H. K., Vesonder, R. F., Boyette, C. D., Hoagland, R. E. and Krick, T. (1992). Production of fumonisins by Fusarium moniliforme culture isolated from Jimson week in Mississipi. J. Phytopathol. 136:199-203.

3. Akinyele, B.J. and Adetuyi, F.C. (2005). Effect of agrowastes, pH and temperature variation on the growth of Volvariella volvacea. Afr J Biotechnol. 4 (12): 1390-1395.

4. Apoga, D., Akesson, H., Jansson, H. B., and G. Odham (2002). Relationship between production of the phytotoxin prehelminthosporol and virulence in isolates of the plant pathogenic fungus Bipolaris sorokinana. Eur. J. Pl. Pathol. 108: 519-526.

5. Barbosa, A. M., Souza, C. G., Dekker, R. F., Fonseca, R. C., and Ferreira, D. T. (2002). Phytotoxin produced by Bipolaris euphorbiae in-vitro is effective against the weed Euphorbia heterophylla. Braz. Arch. Biol. Technol. 45(2): 233-240.

6. Evidete, A., Capasso, R., Andolfi, A., Vurro, M., and Zonno, M.C. (1998). Structure- Activity relationship studies of putaminoxins and pinolidoxins: Phytotoxic nonenolides produced by phytopathogenic Phoma and Ascochyta species. Nat Toxins. 6: 183-188.

7. Gauvrit C. (1994). Methodology for determining foliar penetration of herbicides with reference to oil based adjuvants. Springer Verlag, Berlin. Interactions between adjuvants, agrochemicals and target organisms. pp. 171-191.

8. Graca, M., Bongaerts, J. H., Stokes, J. R. and Granick, S. (2007). Friction and adsorption of aqueous polyoxyethylene (Tween) surfactants at hydrophobic surfaces. J. Colloid Interface Sci. 315(2), 662-670.

9. Greaves, M. P., Dutton, L., and Lawrie, J. (2000). Formulation of microbial herbicides. Aspects. Appl. Biol. 57:171-177.

10. Hoagland, R. E. (1999). Biochemical interactions of the microbial phytotoxin phosphinothricin \& anlogs with plants and microbes. In: Biologically Active natural Products (eds. H.G. Cutler \& S.J. Cutler) Boca Raton FL: CRC Press. pp. 108-125.

11. Hoagland, R. E. (2001). The genus Streptomyces, a rich source of novel phytotoxins In: Ecology of Desert Environment (ed. Ishwar Prakash ) Scientific Publishers Jodhpur (Raj) pp. 139-169.

12. Holm, L. G., Plucknett, D. L., Pancho, J. V., and Herberger, J. P. (1977). The world's worst weeds. University Press.

13. Kalam, S., Pandey A. and Pandey A. K. (2014). Mass production and formulation of herbicidal metabolites from Phoma herbarum FGCC\#54 for management of some prominent weeds of Central India. AIJRFANS. $5(1): 40-47$.

14. Naseem, F., Kalam, S., and Pandey, A. K. (2016). Evaluation of agrochemicals blended with formulants against Hyptis suaveolens. AIJRFANS. 14(1):22-25.

15. Pandey, A. K., Rajak, R. C., and Hasija, S. K. (2001). Biotechnological development of ecofriendly mycoherbicides. In: Innovative Approaches in Microbiology (eds. Maheshwari \& Dubey) Bishen Singh, Mahendrapal Singh, Dehradun. pp 1-21.

16. Pandey, A. K., Singh, A. K., Quereshi, S. and Agrawal, D. (2004) Herbicidal activities of secondary metabolites of Strepomyces sp. against Hyptis suaveolens. J. Basic Appl. Mycol. 3: 95-97.

17. Parra, R., Aldred, D., and Magan, N. (2005). Medium optimization for the production of the secondary metabolite squalestatin S1 by a Phoma sp. combining orthogonal design and response surface methodology. Enzyme Microb. Technol. 37(7):704-711.

18. Quereshi, S., Pandey, A.K., Singh, A.K, Yadav, and K.K. (2006). Herbicidal Potential of Phoma sp FGCCW\# 54: A Preliminary Evaluation. J. Basic Appl Mycol. 5(I\&II):60-62.

19. Quereshi, S. and Pandey, A. K. (2007). Evaluation of the secondary metabolites of Phoma sp Test strain\#54 for management of Parthenium hysterophorus. Indian Phytopathol., 60(4), 462-466.

20. Quereshi, S., Panjawani, R., Pandey, A. K., and Singh, A. K. (2010). Formulation of phytotoxin from Phoma sp. FGCC\#18 for the management of Parthenium hysterophorus L. Arch. Phytopathology Plant Protect. 43(13):1260-1267. 
21. Saraf, A., Quereshi, S., Sharma, K., and Khan, N. A. (2011). Antimicrobial activity of Lantana camara L. J. Exp. Sci. 2(10):50-54.

22. Saxena, S., Pandey, A. K. and Rajak, R. C. (2001). Potential of idiolites from Alternaria alternata as biorational agrochemical. In: Frontiers in fungal Biotechnology and Plant Pathogen relationship (ed. Manoharachary et al.) Allied Publishers, pp. 22-28.

23. Sharma, G. P., Raghubanshi, A. S., and Singh, J. S (2005). Lantana invasion: an overview. Weed Biology and Management, (5), pp. 157-165.

24. Sidana, A. and Farooq, U. (2014). Sugarcane bagasse: a potential medium for fungal cultures. Chinese Journal of Biology, 2014:1-5.

25. Singh, M. and Mack R.E. (1993). Effect of organosilicane- Based adjuvants on herbicide efficacy. Pest Sci,, 38, 219-225.

26. Sharma, M.C., and Sharma, B.C. (1969) Toxic metabolite production by Colletotrichum gloeosporioides causing citrus dieback. Indian Phytopathol. 23: 67-74.

27. Singh, J., Quereshi, S., Banerjee, N., and Pandey, A. K. (2010). Production and Extraction of phytotoxins from Colletotrichum dematium FGCC\#20 Effective against Parthenium hysterophorus L., Braz. Arch. Boil. Technology. 53(3):669-678.

28. Vikrant, P., Verma, K.K., Rajak, R.C., and Pandey, A.K. (2006). Characterization of a phytotoxin from Phoma herbarum for management of Parthenium hysterophorus L. J. Phytopathol. 154:1-8.

29. Walker, H. L. \& G. E. Templeton (1978). In vitro production of phytotoxic metabolites by Colletotrichum gleosporioides f sp. aeschynomene. Plant Sci. Lett. 13: 91-99.

30. Zhang, W., Wolf, T. M., Bailey, K.L., Mortensen, K. and Boyetchko, S. M. (2003). Screening of adjuvants for bioherbicide formulations with Colletotrichum spp. and Phoma spp. Biol. Control. 26: 95-108. 